\title{
Emergency Logistics Theory, Model and Method: A Review and Further Research Directions
}

\author{
Hongqian Xu, Danhui Fang and Yining Jin \\ China Research Center for Emergency Management, Wuhan University of Technology Wuhan Hubei 430070, China
}

\begin{abstract}
With the improvement of people's understanding of disaster relief, emergency logistics has become an important guarantee to improve the efficiency of relief and safeguard the safety of people's lives and property in recent years. In this paper, the research theories, methods and models of emergency logistics are classified and sorted out, and different problems such as Location Allocation Problem, Vehicle Routing Problem, Location-Routing Problem are classified and discussed. Under the condition that most of the existing researches mainly focus on response cost and response time, this paper argues that the primary purpose of emergency logistics should be to reduce the loss of people's lives and property. Based on this, an extension study on emergency logistics is proposed to provide ideas for further research in related fields.
\end{abstract}

Keywords-emergency logisticst; disaster relief; methods and models

\section{BACKGROUND AND CONCEPT}

Emergency logistics refers to the logistics activities caused by emergencies, including emergency logistics demand generated by emergencies and emergency logistics supply activities to meet these logistics needs, pursuing the purpose of maximizing time efficiency and minimizing disaster losses. Facility location and material distribution in emergency logistics is an important part of emergency decision-making and one of the key links of rescue operations[1]. In 2004, scholars first put forward the concept of emergency logistics: logistics activities for the purpose of providing materials needed to deal with natural disasters, public health incidents, major accidents and other emergencies[2]. According to the definition put forward by Tomas and Fritz Institute in 2004, humanitarian logistics is to plan, execute and control the efficient and effective flow and storage of relief materials and related information from the place of supply to the place of consumption.These include preparation, planning, procurement, transportation, warehousing, tracking and tracking, and customs clearance[3].

However, when natural disasters occur, it often causes damage and damage to road facilities, and affects the efficiency of emergency supplies distribution because of various obstacles. The loss of inefficient distribution accounts for about $15 \% \sim 20 \%$ of the total loss of the disaster[4]. Humanitarian logistics for emergency rescue is a very important part of emergency rescue operations, accounting for $80 \%-90 \%$ of the total cost of rescue, according to Fritz Research Institute[5].The transfer speed of the rescue personnel will determine the quality of the whole emergency rescue operation[6]. Therefore, it is of great significance to improve the efficiency of emergency logistics and optimize the ability of emergency logistics. The related theories and research models of emergency logistics described in this paper will mainly focus on the location, transportation and distribution of emergency materials to rescue sites.

\section{CHARACTERISTICS OF EMERGENCY LOGISTICS}

Emergency logistics research includes the emergency allocation, transportation and distribution of materials for emergency relief in disaster areas after the occurrence of sudden natural disasters and social hazards such as earthquakes, floods, hurricanes, mudslides, outbreaks, major traffic accidents, production accidents and terrorist attacks and the delivery of personnel.

Compared with conventional commercial logistics activities, the cost and time of emergency logistics are contrary to each other, and time is more dominant in the goal. Therefore, it has the characteristics of sudden and unpredictable, stochastic demand, urgency of time constraints, peak value, weak economy, unconventionality, government and market participation. In this case, the particularity and continuity of different disaster relief stages should be taken into account in the study of related problems and the construction of models.

\section{ClassificAtion Of EMERGENCY LOGISTICS PROBLEMS}

Scholars generally believe that the key to effectively ensure the supply of emergency supplies lies in rational location Allocation Problem (LAP) and scientific planning of the Vehicle Routing Problem (VRP). Moreover, there is an interdependent and interactional relationship between LAP and VRP, thus it is necessary to design and optimize them as a whole system, that is, to study Location-Routing Problem (LRP) in emergency logistics system.

\section{A. Classification of LAP}

LAP problem mainly refers to the decision-maker determines the number and location of facilities in a certain geographical area according to the geographical distribution of customers and the distribution of goods. It can be roughly divided into the following eight categories. In this paper, typical problems and solution models are selected for analysis: 


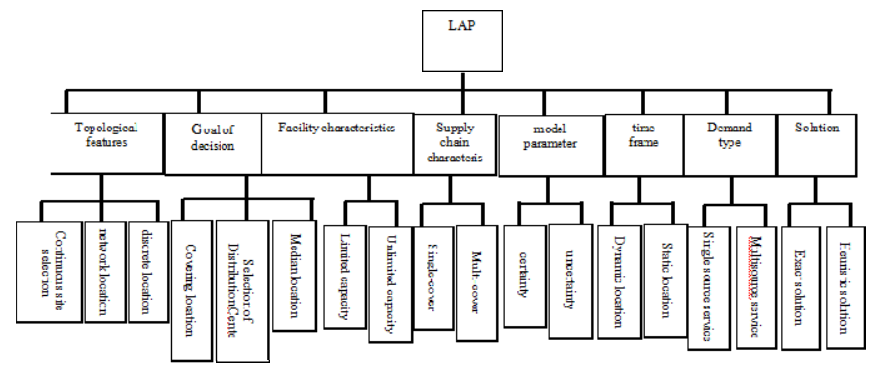

FIGURE I. CLASSIFICATION OF LOCATION ALLOCATION PROBLEMS

\section{1) Site Selection and Allocation}

In the traditional location problem, there are mainly coverage problem, center problem and median problem, and coverage problem is divided into set coverage model, maximum coverage model, maximum available model and so on. These traditional models are based on the assumption that the conditions are determined. Compared with the traditional location problem, the location problem of emergency supplies is stochastic and uncertain. Therefore, some people introduce probability theory and fuzzy theory into the location of emergency facilities[7].

There is also an article on how to determine facilities with uncertain demand by considering the number and distance of services. In the case study of Los Angeles, we use chance constrained model to solve the maximum location coverage problem[8].For capacity facility location problem with single source constraints, some scholars have proposed a VLSN search algorithm and proved its effectiveness[9]. As the problem of uncapacitated facility location (UFL), When the goal is to find a subset of facility locations to open and to allocate each customer to open facilities so that the facility opening plus customer allocation costs are minimized. Scholars use (generalized) Benders cuts to replace a huge number of allocation variables by a small number of continuous variables that model the customer allocation cost directly[10].

\section{2) Research on Dispatch and Allocation}

Emergency materials dispatching and distribution is the management of emergency materials after the outbreak of a sudden disaster event. It is usually necessary to transport all kinds of materials from different locations to several emergency materials distribution centers and disaster areas in the shortest time. Material allocation is the next phase of material dispatching, but in many cases the scheduling and allocation occur simultaneously, so many articles will study the two together.

When some essays study the problem of locating emergency resource reserve sites in cities and towns, taking the rainstorm disaster as the background and Hongshan District of Wuhan as an example, eight suitable emergency resource reserve nodes in the study area are selected from the six basic conditions of locating emergency resource reserve sites under the influence of the determined rainstorm disaster, and then Freud is used. German algorithm calculates the distribution paths with reserve points, and obtains the relationship between the positions of the eight reserve points when the number of reserve points is different, aiming at the shortest total path distance[11].

Some scholars considered the serious shortage of emergency materials and the shortage of emergency supplies in the early post-earthquake period when they studied the location-allocation problem of emergency logistics. In order to meet the different emergency needs of multi-agent participation after the earthquake, and at the same time consider the fairness and efficiency, from the point of view of coordinated distribution of public and private logistics resources, they constructed the maximum and total satisfaction. Multi-period, multi-objective, multi-material dynamic location-allocation model with minimum cost and minimum personnel loss is solved by genetic algorithm with the objective of maximizing the commodity satisfaction rate at the upper level and maximizing the time satisfaction rate at the lower level. Finally, the validity of the model and algorithm is verified by a case study of the Wenchuan earthquake[12].

\section{B. Review of VRP Researches}

VRP studies that in order to meet the customer's demand for goods, delivery time, vehicle capacity constraints, mileage constraints, time constraints, a series of customer demand points for the design of appropriate vehicle routes, and to meet the shortest mileage, the least cost, the shortest time, as small as possible fleet size, vehicle benefits. Optimize the target with higher utilization rate.

In the aspect of distribution routing optimization, it mainly analyzes the degree of road damage and road congestion by constructing road network, and studies the emergency material scheduling problem under the condition of uncertain vehicle travel time.

The Vehicle Routing Problem (VRP) was first proposed in 1959 to study the transportation of gasoline from petrol stations to various gas stations[13]. Under the condition of limited time, limited quantity and quality of resources, the optimal model for allocating and transporting resources to multiple disaster sites after an earthquake is studied with the objective of minimizing the number of deaths[14]. Some scholars classify the distribution of rescue materials as a network flow problem with multiple modes of transportation and multi-material categories, and construct a dynamic distribution model with time constraints. The objective function is to minimize the amount of emergency materials that do not meet the demand[15]. Considering the Vehicle Routing Problem (VRP), some scholars have studied the sub-path ejection chain method under the limit of capacity and path length[16]. A stochastic vehicle routing model is proposed to solve the evacuation problem of flood victims[17]

\section{Studies on LRP}

Researchers on Location-Routing Problems (LRP) mainly focus on theoretical model and algorithm design. In the actual operation of emergency logistics system, the location of distribution center and the choice of distribution route are interdependent, mutually reinforcing. The location of distribution center will affect the planning of distribution route, and the optimization of distribution route will affect the 
location of distribution center in turn. Therefore, it is necessary to consider the distribution of emergency logistics from the overall point of view from the perspective of the post-disaster emergency logistics distribution system.

At present, the interpretation models of LRP mainly include facility location decision model [18], robust programming [19], two-stage random mixed integer programming model [20], etc. In addition, some scholars have studied the LRP model with uncertain parameters. Such as introducing randomness into the model, transformed stochastic variable demand into deterministic demand, and constructed a LRP model with multiple supply points and multiple vehicle Location-Routing for single objective optimization cost[21]. Many others studied the integrated optimization model of multi-mode, multi-stage, multi-objective emergency material allocation and multi-mode transportation under fuzzy conditions, and realized the dynamic location of emergency facilities and the optimal dispatch of emergency materials through multi-objective dynamic weighting[22].

\section{OTHER STUDIES ON EMERGENCY LOGISTICS}

\section{A. Disruption Management of Logistic}

In the aspect of disruption management, there is little research on the disruption management of post-disaster LRP. Scholars often carry out modeling and verification under ideal hypothesis. In fact, this research will help to improve the efficiency of post-disaster rescue greatly.

In addition to multi-objective interference, LRP is often confronted with many uncertain factors in the process of emergency materials distribution after disasters. For example, road damage, sudden large-scale outbreak of the epidemic led to a sharp increase in demand for emergency supplies at some demand points, vehicles in the course of service failure can not continue to distribute, demand points require early delivery of emergency supplies. Such incidents are collectively referred to as interference events. At this point, if the decision-maker supplies emergency materials according to the initial plan made before the interference incident, it will inevitably lead to the failure of some demand point services.

Therefore, it is necessary to adjust the plan according to the specific situation of the disturbance events, effectively deal with the disturbance events, so as to minimize the disturbance to the emergency logistics system after the earthquake, and ensure the normal distribution of emergency supplies.

In disruption management, the problem of site selection for facility damage scenarios was first proposed in 1987. Some researches analyzed four causes of facility failure, and then studied the p-center model and p-median model for facility damage scenarios[23]. Some others considered the different failure probability of facilities in different locations, and introduced the failure of facilities, established a supply network considering both reliability and economic benefits, and proposed two unrestricted reliability location models[24]. Some essays considers possible damage scenarios in the process of emergency facility location optimization, and establishes a multi-objective optimization model for emergency facility location[25]. The total rescue time covering the target reflects the timeliness, the maximum rescue radius reflects the equilibrium, and the additional rescue change time under the situation of facility damage reflects robustness. For rod property, a target disturbance minimization model based on ideal point is proposed, and a genetic algorithm is used to design and solve the model.

Further more, study on the real-time decision-making method of disturbance events in the location-routing problem of emergency materials distribution in the early postearthquake period. Considering the damage of road network, fuzzy demand of demand points and multi-mode distribution, the LRP optimization model of post-earthquake emergency logistics is constructed with the shortest total distribution time of emergency materials. Two kinds of disturbance events, i.e. the serious damage of the original unblocked road caused by aftershocks, the impassability of vehicles and the failure of vehicles requiring maintenance, were tested.

\section{B. Transportation of the Wounded}

Choosing an objective function which is close to the interests of the wounded and sick to evaluate the effect of emergency rescue effectively is the research direction of many scholars. According to the theory of timeliness of rescue in emergency medicine, the deterioration of severely injured patients mostly occurs in a very short time after injury. It is a key to reduce the mortality of severely injured patients by making them receive treatment in the "golden first aid time" as far as possible. The value of first aid. Because of the proximity of the clusters of heavy and light casualties in the spatial distribution, it is necessary to make a comprehensive plan for the treatment and transfer of the heavy and light casualties in the formulation of the ambulance treatment and transfer vehicle routing planning.

In the study of emergency logistics, in order to achieve a large-scale natural and accident disaster casualties after the rapid treatment and placement, according to the casualties can be classified into high-efficiency casualty treatment and transfer rescue model. By introducing the theory of timelimited treatment of the wounded into the trauma index to calculate the changes of the severity of the wounded during the waiting period, and taking the minimization of the total trauma index of the wounded as the optimization objective, the priority levels of the severity of the wounded during the early and late rescue periods are dynamically adjusted, and the routes of ambulance treatment and transfer of the wounded are planned as a whole, so as to make the wounded and so on. The severity of the injury was reduced to the minimum during the period. Some scholars have established a multi-distance, demandseparable ambulance VRP mathematical model, and designed a distance-based neighborhood search model fast solution algorithm, more in line with the large-scale emergency time ambulance between the hospital and the casualty cluster to carry out rapid rescue requirements, and finally validated by numerical simulation and comparative study. The effectiveness of the model and algorithm[27]. 


\section{Summary Of SOlutions AND MOdels To EMERGENCY LOGISTICS PROBLEMS}

At present, the research structure of many papers on emergency logistics is mainly problem description - problem hypothesis - model construction (selection of objectives, constraints) - planning solution / algorithm design - Example Analysis - effect evaluation (validity / rationality validation)

\section{A. Forecasting Method of Material Demand in Emergency Situation}

- $\quad$ The demand for emergency supplies can be forecasted by a series of data consisting of pre-demand, such as grey system model forecasting method;

- Analogy Principle: Emergency supplies demand can be predicted by looking for similar cases, the core idea is to use the experience of previous similar problems and acquired knowledge to infer the current problem solution. For example, case-based reasoning, BP neural network;

- Relevant Principle: Emergency supplies demand is affected by many factors, based on the linear hypothesis between demand and factors to do correlation analysis. For example, multiple regression model prediction method and indirect prediction method.

\section{B. Dispatching and Allocation Solutions}

1) Research on Optimization Theory based on Operational Research

From the point of view of optimization, it can be divided into single objective optimization and multi-objective optimization. The objectives include the minimum transportation cost, the shortest emergency time, the least unmet quantity, the least number of deaths, the least transportation time and so on.

For example, in order to minimize the total cost and transport risk, scholars have established a multi-objective LRP model, which solves the problem of waste recycling station location and arranges the routes of different types of waste to these different recycling stations[28]. For LRP, a single objective bi level satisfaction model[31] is constructed under the conditions of minimizing transportation cost[29], minimizing transportation time[30] or time satisfaction[31]. The single objective LRP problem neglects the fixed cost of facilities when calculating the cost, which is different from the actual operation. For this reason, some scholars have studied the multi-objective LRP model.

\section{2) Combinatorial Mathematics Method}

When studied the LRP of emergency materials distribution after disaster, a multi-objective LRP decision-making model was constructed with the objective of minimizing warehouse construction cost and operation cost and maximizing demand coverage, and a mathematical heuristic algorithm was designed to solve it[32].

\section{3) Other Theories and Model Solving Methods}

In addition to the network flow model commonly used in material transportation and distribution, there are also Bayesian decision theory, feedback control theory, staged decisionmaking, credibility model, scenario planning method, genetic algorithm and so on.

For example, a multi-objective open LRP optimization model is constructed to minimize the total arrival time, the total cost and the reliability of emergency supplies, and a nondominated sorting genetic algorithm and a non-dominated sorting differential evolution algorithm are designed to solve the model[33]. Or in the theory of stage-wise decision-making, a three-stage mixed-integer stochastic programming LRP model is constructed, which considers the uncertainties of demand, the limitation of vehicle capacity and the condition of emergency logistics network in the distribution of emergency materials. The first stage solves the problem of locating logistics center, and the second stage carries out the vehicle of logistics center. The third stage is to deal with the uncertainty of emergency logistics network[34].

\section{CORRELATION EXTENSION STUDY}

Through the review and Research on the field of emergency logistics, there are still some deficiencies in the related extended research from the following perspective. Scholars can expand their research accordingly.

1) Considering the perceived fairness of emergency logistics from the perspective of disaster victims' psychology.

2) Considering the process of post-disaster material distribution as a process of game theory, using game theory to solve the problem of fairness of post-disaster distribution.

3) At present, most of the articles are carried out from the perspective of decision makers. Post-disaster relief has the attribute of multi-agent participation. How to think and discuss from the perspective of other subjects (disaster victims, logistics executives).

4) From the perspective of disaster chain, we should consider the inventory management of distribution centers or distribution centers.

5) Considering the reverse logistics in emergency logistics.

\section{REFERENCES}

[1] Guo Zixue,Guo Liang,Zhang Pei,Yang Xiaohui, "Fuzzy optimization model for minimizing emergency material dispatch time”. China Safety Science Journal, vol 25, no.10, pp.172-176, 2015.

[2] Ou Zhongwen, Wang Huiyun, "Emergency Logistic," Journal of Chongqing University, 2004, pp.164-167.

[3] Tomas. A, "Leveraging private expertise for humanitarian supply chains," Forced migration Review, vol. 21, pp. 64-65, 2004.

[4] Gao Hongni, Zhao Yibing, Li Ning. "Study on earthquake disaster emergency supplies scheduling model based on multiple demand points,” China Safety Science Journal, vol.23, no.01, pp.161-165, 2013.

[5] Taylor, D, Pettit, S, “A consideration of the relevance of lean supply chain concepts for humanitarian aid provision,” International Journal of Services, Technology and Management, vol.12, no.4, pp. 430-444, 2009. 
[6] CHAIKEN, J.M. and LARSON, R.C., 1972. "METHODS FOR ALLOCATING URBAN EMERGENCY UNITS: A SURVEY,” Management Science (pre-1986), vol.19, no.4, pp. 21.

[7] Chen Gang, Zhang Jin, Fu Jiangyue, “A multi-objective locationallocation model for emergency logistics in an uncertain information environmen,” China Safety Science Journal, vol.26, no.12, pp.163-168, 2016.

[8] Murali P, Ordóñez F, Dessouky MM, "Facility location under demand uncertainty: Response to a large-scale bio-terror attack," SocioEconomic Planning Sciences, vol.46, no.1, pp.78-87, 2012.

[9] Ahuja R, Orlin J, Pallottino S, Scaparra M, Scutellà M, “A MultiExchange Heuristic for the Single-Source Capacitated Facility Location Problem,” Management Science [serial online], vol.50, no.6, pp.749-760 2004.

[10] Fischetti, Matteo, "Redesigning Benders Decomposition for Large-Scale Facility Location,” Management Science, vol.63, no.7, pp. 2146-2163, 2017.

[11] WU Ke, SONG Yinghua, LYU Wei, "Research on siting of urban emergency resources depots and layout optimization considering rainstorm disaster and distribution route,” China Safety Science Journal, Vol.27, No.9, pp. 170-174, 2017.

[12] SONG Yinghua, NING Jingjing, LYU Wei, DU Lijing, "Research on dynamic LAP model of emergency logistics public-private collaboration in aftermath of earthquake,” China Safety Science Journal, Vol.28, No.3, pp. 173-178, 2018.

[13] Dantizig G, Ramser J. “The Truck Dispatching Problem,” Management Science, 1959, vol.6, pp.80-91.

[14] Fiedrich, Gehbauer, Rickers. "Optimized resource allocation for emergency response after earthquake disasters,” Safety Science, 2000, vol, 35, no.1, pp. 41-57.

[15] Linet Odamar, Ediz Ekinci, Beste Kucukyazici. The Dynamics of Emergency Transshipment Supply Chains. Annals of Operations Research, 2004, pp.217-245.

[16] Rego C. "A Subpath Ejection Method for the Vehicle Routing Problem. Management Science [serial online],” October 1998, vol.44, no.10, pp.1447-1459. Available from: IT Source, Ipswich, MA. Accessed June 3, 2018.

[17] DESSOUKY M, ORDONEZ F, JIA H. "Rapid distribution of medical supplies,” Patient Flow: Reducing Delay in Healthcare Delivery, 2013, pp.385-410.

[18] CHEN Gang, ZHANG Jin, FU Jiangyue. “A multi-objective locationallocation model for emergency logistics in an uncertain information environment,” China Safety Science Journal, vol.26, no.12, pp.163-168, 2016.

[19] WANG Jing, ZHANG Ling, HUANG Jun. "The robust emergency logistics system based on uncertain demand," Mathematics in Practice and Theory, vol. 39, no.20, pp. 53-60, 2009

[20] RAW LS C G, TUMQUIST M A. "Pre-positioning of emergency supplies for disaster response," Transportation Research Part B: Methodological, vol. 44, no.4 pp. 521-534, 2010.

[21] Chan Y, Baker SF. “The multiple depot, multiple traveling salesmen facility-location problem: Vehicle range, service frequency, and heuristic implementations,” Mathematical and Computer Modelling. Vol.41, no.8, pp.1035-53, 2005

[22] Song yinghua, Wang lifag. "Location-multimodal transportation problem for relief distribution in emergency logistics under fuzzy conditions,” China Safety Science Journal, vol.27, no.7, pp.169-174, 2017.

[23] Drezner, Zvi. "Heuristic Solution Methods for Two Location Problems with Unreliable Facilities,” The Journal of the Operational Research Society, vol.38, no. 6 (1987), pp. 509-514

[24] Cui, Tingting, Yanfeng Ouyang, and Zuo-Jun Max Shen. "Reliable Facility Location Design Under the Risk of Disruptions,” Operations Research, vol. 58, no. 4 (2010), pp. 998.

[25] Zhu Jianming. "Methods of multi-objective decision-making for emergency facility location problem under failure scenario," Systems engineering-Theory \& Practice, 2015, vol.35, no.3, pp.720-727.
[26] LIU Changshi, ZHU Zheng, LIU Liyong. "Disruption management of Location-Routing Problem (LRP) for emergency logistics system in early stage after earthquake,” Computer Engineering and Applications, 2017, vol.53, no.20, pp.224-230.

[27] WANG Jing;LIU Hao-tian;Huang Jun, "Research on the Route Optimization of Ambulance Treatment and Transportation after Disaster Based on the Injured Classification,” Chinese Journal of Management Science, Vol.25, No.8, pp.114-122,2017.

[28] Alumur S, Kara BY. "A new model for the hazardous waste locationrouting problem. Computers and Operations Research,” vol.34, no.5. pp. 1406-23, 2007.

[29] EQUI L, GALLO G, MARZIALE S. “A combined transportation and scheduling problem,” European Journal of Operational Research, vol.97, no.1, pp.94-104, 1996.

[30] YU Wuyang, “Transshipment model for emergency materials based on time satisfaction criterion,” Journal of Systems \&Management, 2013, vol.22, no.5, pp.882-887.

[31] KONGSOMSAKSAKUL S, YANG C, CHEN A. "Shelter locationallocation model for flood evacuation planning," Journal of the Eastern Asia Society for Transportation Studies,2005,vol.6,pp.4237-4252.

[32] Rath S, Gutjahr W J. "A math- heuristic for the ware-house locationrouting problem in disaster relief,” Computers \& Operations Research, vol.42, pp.25-39, 2014

[33] Wang H. "Multi-objective open location-routing model with split delivery for optimized relief distribution inpost-earthquake," Transportation Research Part E: Logistics and Transportation Review, 2014, vol.69, pp.160-179.

[34] Rennemo S J, Ro K F, Hvattum L Ml. “A three-stage stochastic facility routing model for disaster response planning," Transportation Research Part E:Logistics and Transportation Review, 2014,vol.62,pp.116-135. 